\title{
O CONCEITO DE INCLUSÃO DE DISCENTES DE EDUCAÇÃO FÍSICA DE UNIVERSIDADES PÚBLICAS DO ESTADO DE SÃO PAULO NO CONTEXTO SOCIAL DA SUA PRÁTICA
}

\author{
THE CONCEPT OF INCLUSION OF PHYSICAL EDUCATION STUDENTS FROM \\ PUBLIC UNIVERSITIES IN THE STATE OF SÃO PAULO, BRAZIL, IN THE SOCIAL \\ CONTEXT OF ITS PRACTICE
}

\author{
EL CONCEPTO DE INCLUSIÓN DE ALUMNOS DE EDUCACIÓN FÍSICA DE \\ UNIVERSIDADES PÚBLICAS DEL ESTADO DE SÃO PAULO/BRASIL EN EL \\ CONTEXTO SOCIAL DE SU PRÁCTICA
}

\section{Marina Brasiliano Salerno*, Camila Lopes de Carvalho**, Silvia Mayeda D’Angelo**, Paulo Ferreira de Araújo**}

Palavras chave: Educação Física e Treinamento. Inclusão Educacional. Formação de Conceito.
Resumo: A formação inicial em Educação Física tem se reconstruído segundo os paradigmas inclusivos em implantação na sociedade. Assim, este estudo objetivou verificar 0 conceito de inclusão apresentado por estudantes universitários concluintes do curso de Educação Física em instituições públicas do estado de São Paulo. Para isso, foi desenvolvida uma pesquisa qualitativa por meio da aplicação de questionário a 322 acadêmicos. Os dados foram analisados pelo programa Iramuteq, por meio das análises de Classificação pelo Método de Reinert, Análise de Similitude e Nuvem de Palavras. Como resultado, foi identificado que os discentes respondentes têm alcançado a construção de um conceito de inclusão condizente com a complexidade do princípio, considerando aspectos legais, sociais, psicológicos e afetivos imbuídos nessa proposta.

Keywords: Physical Education and Training. Educational Inclusion. Concept Formation.

Palabras clave: Educación Física y Entrenamiento. Inclusión Educacional. Formación de Concepto.
Abstract: Initial training in Physical Education has been rebuilt according to inclusive paradigms being established in society. This study looks into the concept of inclusion presented by senior Physical Education college students at public institutions of the state of São Paulo. Qualitative research was conducted through questionnaires answered by 322 students. Data were analyzed using Iramuteq software by Reinert Classification analysis. The results showed that students built a concept of inclusion compatible with the principle of complexity, considering legal, social, psychological and affective characteristics included in that proposition.

Resumen: La formación inicial en Educación Física se ha reconstruido según los paradigmas inclusivos en implantación en la sociedad. Así, ese estudio objetivó verificar cuál es el concepto de Inclusión presentado por los estudiantes universitarios que concluyen el curso de Educación Física en instituciones públicas del estado de São Paulo. Así, se desarrolló una investigación cualitativa a través de la aplicación de cuestionario a 322 académicos. Los datos fueron analizados con el programa Iramuteq, empleando los análisis de Clasificación por el Método de Reinert, Análisis de Similitud y Nube de Palabras. Como resultado, se ha identificado que los alumnos participantes han alcanzado la construcción de un concepto de Inclusión de acuerdo con la complejidad del principio, considerando aspectos legales, sociales, psicológicos y afectivos incluidos en esa propuesta.
*Universidade Federal de Mato Grosso do Sul. Campo Grande, MS, Brasil. E-mail: marina.brasiliano@gmail.com

**Universidade Estadual de Campinas. Campinas, SP, Brasil. E-mail: camilalopes.c@ hotmail.com; silviamayeda@gmail.com; paulof@fef.unicamp.br

Recebido em: 16-11-2017 Aprovado em: 31-05-2018

DOI: https://doi.org/10.22456/1982-8918.78055 (c) (1) (8) Licence 


\section{INTRODUÇÃO}

Desde as primeiras formas de organização social há uma contínua imposição e reconstrução de paradigmas que incidem sobre a valoração ou depreciação de seus partícipes, segundo a relação entre as características apresentados pelos indivíduos e os aspectos culturais e político-econômicos de cada nação.

Concernente às pessoas com deficiência, o cenário social delineado até a proximidade do século XX apresentou-se predominantemente discriminatório, com rejeição, abandono e condenações à morte aos que possuíssem tais condições, devido à influência de explicações místicas que as associavam aos pecados ou maus espíritos. Desde então, alterações consubstanciais acerca tanto dos conhecimentos científicos racionais quanto dos direitos humanos à cidadania estenderam-se às pessoas com deficiência, substituindo vagarosamente a exclusão de caráter místico por um princípio de aceitação dessa população na sociedade em busca de uma possível contribuição destas ao desenvolvimento político-econômico almejado.

Esse transcurso evidenciou-se por três fases, das quais a principiante foi conceituada de Normalização por Bank-Mikhelsen, na Dinamarca, em 1959, com as primeiras refutações contundentes acerca da exclusão social até então imposta às pessoas com deficiências, bem como com a investigação de métodos para proporcionar-hhes atividades e costumes semelhantes aos vivenciados na sociedade, ainda que dentro de instituições especiais (SMITH, 2008). Entre 1960 e 1970, a fase de Integração a sucedeu, intencionando-se retirá-las dessas instituições e adaptá-las para que se inserissem e participassem da mesma forma que os demais indivíduos nos variados ambientes sociais. Contudo, as dificuldades para integrálas despontavam, uma vez que os seus limites impediam uma atuação conforme o padrão convencional exigido. Interrogando tal processo de inserção social, entre 1980 e 1990, o princípio inclusivo despontou como terceira fase, atribuindo à sociedade, e não mais à pessoa com deficiência, a função de se adaptar para permitir a participação de todos na sua estrutura e função; todas as suas atividades, espaços e serviços instituídos há decênios e centenários foram exigidos que se adequassem para possibilitar a atuação de todos com qualidade (SILVA; SEABRA JUNIOR; ARAÚJO, 2008).

Nesse contexto, a atuação da Educação Física também careceu de ajustes. Após centenários de práticas direcionadas ao alcance de aptidões físico-motoras segundo uma predefinição de eficiência que excluía os menos habilidosos ou com dificuldades, em 1952, foi principiada a reestruturação da área com a definição do termo "Educação Física Adaptada" (EFA), pela American Association for Health, Physical Education and Recreation (Associação Americana de Saúde, Educação Física e Recreação). Essa nomenclatura se referiu a uma subárea da Educação Física destinada a atender pessoas com diferentes necessidades dentro de seu grupo de alunos, exigindo a adaptação das atividades segundo as suas necessidades e características e desenvolvendo um planejamento de aulas com foco nas potencialidades individuais e não em suas dificuldades (SILVA; ARAÚJO, 2012; SILVA; SEABRA JUNIOR; ARAÚJO, 2008; WINNICK, 2004).

Corroborando essa reconstrução, em 1978 foi aprovada a Carta Internacional de Educação Física e Desportos, pela Conferência da Organização das Nações Unidas, assegurando a Educação Física e o desporto como um direito de todos, inclusive das pessoas com deficiência. Com esse documento, aos professores de Educação Física dos variados 
contextos da prática foi imposta a responsabilidade de desenvolver sua atuação de forma a garantir a participação e o desenvolvimento integral de todos os alunos (UNESCO, 1981).

Para o alcance dessa ação, a formação docente necessitou de novas reflexões segundo os conceitos inclusivos articulados. Em 1987, a Resolução n- 03, do Conselho Federal de Educação implantou a disciplina "Educação Física Adaptada" nos cursos superiores de Educação Física, destinada ao trabalho com conhecimentos relacionados à pessoa com deficiência e às adaptações das atividades físicas a sua condição. Já por meio da Resolução nº 7, de 2004, esse Conselho instituiu as Diretrizes Curriculares (DC) para os cursos de graduação dessa área, determinando que questões relacionadas à diversidade, como referentes às pessoas com deficiência e especificidades regionais e culturais, fossem exploradas durante a formação nesse nível de ensino (SILVA; ARAÚJO, 2012).

Associada à abertura de capacitação docente para trabalhar com essa população, a construção de conhecimentos para promover tal formação mostrou-se impreterível, e teve contribuição relevante das universidades públicas paulistas, com a implantação dos primeiros programas de pós-graduação nível stricto sensu da área direcionados à construção de conhecimentos e ao preparo de profissionais qualificados para a atuação inclusiva (GORGATTI; COSTA, 2005).

Averigua-se um cenário no qual ações recentes e iniciais nas últimas décadas ambicionam superar uma atuação centenária de exclusão dos possuidores de dificuldades. Pode-se depreender que a construção do conceito de inclusão alude a uma conscientização sobre a transformação histórica acerca da participação social da pessoa com deficiência, influenciando as práticas a serem empreendidas na Educação Física, bem como a compreensão dos professores sobre quais os seus deveres enquanto profissionais, os direitos de seus alunos e as possibilidades e necessidades de adequações de suas ações em direção a essa população.

Levando em consideração que o conhecimento conceitual implica diretamente na qualidade das aulas que as pessoas incluídas nesse ideal receberão, este estudo verificou 0 entendimento de inclusão apresentado por estudantes universitários concluintes de instituições públicas do estado de São Paulo, as quais também desempenham a construção teórica para a área.

\section{METODOLOGIA}

A presente pesquisa se caracterizou como qualitativa, conforme o delineamento descrito abaixo.

\subsection{Participantes}

contou-se com uma amostra de conveniência (não probabilística) de 322 estudantes concluintes de cursos de Educação Física em instituições públicas do estado de São Paulo. Tais instituições, em sua composição, podiam apresentar a oferta de cursos de Educação Física em diferentes cidades, que foram chamadas de unidades. Assim, contabilizamos um total de 17 unidades que oferecem curso específico, das quais 16 participaram da pesquisa. 
Do total de acadêmicos participantes, 130 finalizavam a licenciatura, 147 o bacharelado e 45 se graduavam na segunda modalidade.

\subsection{Instrumentos}

Os participantes responderam a um questionário elaborado pelos pesquisadores contendo questões abertas e fechadas referentes à formação voltada ao trabalho com a pessoa com deficiência; tal instrumento foi validado por duas professoras especialistas na área e passou pelo projeto-piloto para verificação de sua adequação. Neste artigo, apresentamos a análise da seguinte questão: "Descreva, da melhor forma possível, o seguinte termo: Inclusão".

\subsection{Procedimento}

os pesquisadores contataram as instituições de ensino a fim de obter permissão para proceder com a pesquisa, enviando uma cópia do questionário a ser aplicado. Após autorização, professores que ministravam aula no último semestre dos cursos foram consultados para cederem espaço em sua disciplina para que os acadêmicos pudessem preencher o questionário, sendo que duas das pesquisadoras foram até a instituição para aplicação aos acadêmicos presentes no dia da coleta dos dados, levando o Termo de Consentimento Livre e Esclarecido àqueles que desejaram participar como voluntários. Com a presença das pesquisadoras, dúvidas foram sanadas, entretanto, elas versaram sobre aspectos da pesquisa e do termo de consentimento, e não sobre o questionário.

O tempo médio para concluir a participação no estudo foi de 20 minutos. Este estudo obteve aprovação do Comitê de Ética em Pesquisa, da Faculdade de Ciências Médicas da Universidade Estadual de Campinas (Parecer $n^{\circ}$ 812/2011), respeitando-se os princípios éticos em conformidade com a Resolução CNS no 510/16.

\subsection{Análise de dados}

para a análise dos dados, as respostas dos participantes foram importadas para 0 programa Open Office Writer, sendo posteriormente lidas pelo programa Iramuteq (Interface de $R$ pour les Analyses Multidimensionnelles de Textes et de Questionnaires) (RATINAUD, 2009), hospedado no software $R$ ( $R$ Development Core Team, 2011). Foram consideradas as seguintes análises (CAMARGO; JUSTO, 2013; RATINAUD, 2009):

a) Classificação pelo método de Reinert. Nesta análise se realiza uma classificação hierárquica descendente (CHD), na qual os segmentos de texto são classificados de acordo com seus vocábulos e o conjunto resultante é dividido com base na frequência das formas reduzidas, formadas a partir do radical das palavras (lemmatisation);

b) Análise de similitude. Esta apreciação se fundamenta na teoria dos grafos e identifica as co-ocorrências entre as palavras, resultando em indicações de conexões entre elas e identificando a estrutura do banco de dados (corpus);

c) Nuvem de palavras. Esta averiguação representa graficamente e organiza as palavras de acordo com as suas frequências por meio da figura gerada a partir do corpus. 


\section{RESULTADOS E DISCUSSÕES}

O corpus analisado foi constituído por 323 segmentos de texto (ST). Observou-se uma média de 14,78 (número de palavras com radicais distintos no texto) por ST, com um total de 4.758 ocorrências (total de palavras contidas no corpus) e apresentando uma divisão total em 266 ST, representando os $82,61 \%$ do total do corpus classificado na análise. Inicialmente, realizou-se a CHD, identificando quatro classes distintas que foram delineadas de acordo com seus descritores mais representativos.

A Classe 1 (STClasse1 = 76, explicando $28,57 \%$ do total) foi denominada de "Participação". Essa classe é representada por elementos referentes às aproximações daqueles alijados da sociedade, tendo o indivíduo como agente de sua vida, podendo esse sujeito apresentar ou não uma condição de deficiência (e.g., atividade, participar, pessoa sem deficiência, conseguir). Na presente classe foram priorizadas as questões de realização por parte da pessoa com deficiência, enfatizando a necessidade de unir essas pessoas para a participação em atividades diversas (e.g., "atividade realizada para uma pessoa ou grupo de pessoas com deficiência com o intuito de que isso os torne pessoas que se sintam à vontade no seu ou em qualquer outro grupo, seja de pessoas com deficiência ou não").

A Classe 2 (STClasse2 = 99, explicando 37,22\% do total) foi nomeada de "Contexto social para a inclusão" devido às principais palavras que a representam (e.g., sociedade, meio, maneira, inserção). Nesta classe se verificou maior ocorrência de palavras que denotam a ação que permeia o pensamento sobre a Inclusão como um movimento da sociedade inserindo aqueles alijados (e.g., "Processo no qual as pessoas com deficiência são incluídas na sociedade, em diversos ambientes por uma mudança de todos os envolvidos, ou seja, a mudança para a inclusão efetiva deve ocorrer por parte da pessoa e da sociedade, se trata de um termo bilateral, o termo inclusão não se referente apenas à pessoa com deficiência, mas também às outras pessoas com necessidades específicas ou não").

A Classe 3 (STClasse3 = 34, explicando 12,78\% do total), denominada de "Oportunizar o acesso", foi resultado dos vocábulos mais elucidados nos segmentos de texto (e.g., oportunidade, acessibilidade, igualdade). Esta se caracterizou pelos aspectos necessários para que as pessoas com deficiência possam ter garantida a acessibilidade aos espaços, com quesitos que permeiam aspectos arquitetônicos, atitudinais e de direitos (e.g., "inclusão seria inserir a pessoa com deficiência na sociedade de forma integral, dando as mesmas oportunidades e opções, seja de saúde, lazer ou trabalho").

A Classe 4 (STClasse4 = 57, explicando $21,43 \%$ do total) foi designada de "Sentimento de Pertença", como resultado das principais palavras que a representam (e.g., grupo, sentir, socialização). Esta classe foi caracterizada pelo sentimento da pessoa com deficiência frente à inclusão, ou seja, considerar-se parte de um grupo foi percebido como um elemento necessário à inclusão (e.g., "fazer com que a pessoa faça parte de um grupo e não seja apenas uma pessoa de corpo presente, mas que participe totalmente ou pelo menos até onde ela se sentir à vontade").

Isto posto, no Quadro 1, estão expostos os ST mais frequentes das quatro classes mencionadas. 
Quadro 1 - Segmentos de texto mais representativos de cada classe.

\begin{tabular}{|c|c|}
\hline$\chi^{2}$ & Segmentos de Texto $\left(\chi^{2}\right)$ \\
\hline \multicolumn{2}{|r|}{ Classe 1} \\
\hline 71,95 & $\begin{array}{l}\text { "É não olhar para a limitação de cada aluno com ou sem deficiência, mas sim valorizar suas } \\
\text { capacidades e habilidades todos dentro de uma mesma atividade." }\end{array}$ \\
\hline 37,22 & $\begin{array}{l}\text { "Ato de tornar parte de um grupo maior um indivíduo que esteja socialmente segregado ou estará } \\
\text { em atividade onde apenas certo grupo possa participar." }\end{array}$ \\
\hline 24,47 & $\begin{array}{l}\text { "Quando a pessoa com deficiência consegue realizar tarefas semelhantes às da pessoa sem } \\
\text { deficiência, claro que com adaptações e adequações necessárias." }\end{array}$ \\
\hline 21,85 & $\begin{array}{l}\text { "Atividade realizada para uma pessoa ou grupo de pessoas com deficiência com o intuito de que } \\
\text { isso os tornem pessoas que se sintam à vontade no seu ou em qualquer outro grupo, seja de } \\
\text { pessoas com deficiência ou não." }\end{array}$ \\
\hline 21,04 & $\begin{array}{l}\text { "Sem qualquer restrição de níveis sociais ou até mesmo de deficiência a inclusão é a aglutinação } \\
\text { de todos os públicos, no caso da pessoa com deficiência e da pessoa sem deficiência." }\end{array}$ \\
\hline \multicolumn{2}{|r|}{ Classe 2} \\
\hline 35,53 & "Processo que inclui pessoas que teoricamente seria ou são esquecidas pela sociedade." \\
\hline 30,45 & $\begin{array}{l}\text { "Inclusão seria uma maneira de colocar no meio de todos uma pessoa que não faça parte } \\
\text { daquele grupo, inclusão não é especificamente para a pessoa com deficiência." }\end{array}$ \\
\hline 23,06 & $\begin{array}{l}\text { "A inclusão é a maneira de permitir uma participação igualitária de segmentos sociais antes não } \\
\text { incluídos em um contexto social que englobe práticas diversas." }\end{array}$ \\
\hline 19,36 & $\begin{array}{l}\text { "Possibilidade de unir grupos heterogêneos nos quais a pessoa com deficiência participa e } \\
\text { interage com diversos outros grupos possibilitando aprendizado e experiências positivas para } \\
\text { todos." }\end{array}$ \\
\hline 19,34 & "A inserção da pessoa com deficiência na sociedade." \\
\hline \multicolumn{2}{|r|}{ Classe 3} \\
\hline 50,44 & "Dar oportunidades iguais a todos, proporcionando a vivência de alguma coisa para todos." \\
\hline 45,59 & $\begin{array}{l}\text { "Incluir ou fazer com que a pessoa com deficiência tenha a mesma condição de acesso à prática } \\
\text { e as mesmas oportunidades de pessoas sem deficiência." }\end{array}$ \\
\hline 41,30 & "É o fato de incluir e tornar as coisas e locais apropriados para todo e qualquer tipo de pessoa." \\
\hline 35,04 & "Permitir que todos tenham condições justas de fazer as mesmas coisas." \\
\hline 34,77 & $\begin{array}{l}\text { "Interação entre sujeitos com deficiência e sem deficiência, sem que haja prejuízo para nenhuma } \\
\text { das partes." }\end{array}$ \\
\hline \multicolumn{2}{|r|}{ Classe 4} \\
\hline 28,40 & "Estar dentro de um grupo, pertencer a uma sociedade e se sentir parte do todo." \\
\hline 21,94 & $\begin{array}{l}\text { "Inclusão é diferente de agregar ou integrar, é amplo no sentido de acolher e fazer a pessoa com } \\
\text { deficiência se sentir parte do todo ativamente, podendo explorar seus potenciais e capacidades." }\end{array}$ \\
\hline 16,12 & "O ato de aproximar as pessoas que estão afastadas ou longe de algo." \\
\hline 15,27 & $\begin{array}{l}\text { "Inclusão são pessoas diferentes interagindo não deixando que as diferenças impeçam a } \\
\text { aproximação." }\end{array}$ \\
\hline 14,89 & "Proporcionar a socialização para todos." \\
\hline
\end{tabular}

Fonte: Os autores.

Já no Quadro 2 estão representadas as classes com seus respectivos vocábulos. Ressalta-se que no presente estudo foram selecionados apenas os vocábulos que atenderam ao critério preestabelecido $\left[\chi^{2}(1) \geq 3,84, p<0,05\right]^{1}$.

10 critério preestabelecido se refere ao valor significativo tendo em conta a tabela de distribuição na qual valores de Qui quadrado foram $\geq$ que 3,84, com grau de liberdade 1 e significância 0,05 . Qui quadrado é um teste de hipótese que avalia a associação entre variáveis qualitativas, sendo grau de liberdade indicativo da semelhança entre variáveis experimentais-teóricas e significância a probabilidade de erro ao se rejeitar uma hipótese (TABACHNICK; FIDELL, 2013). 

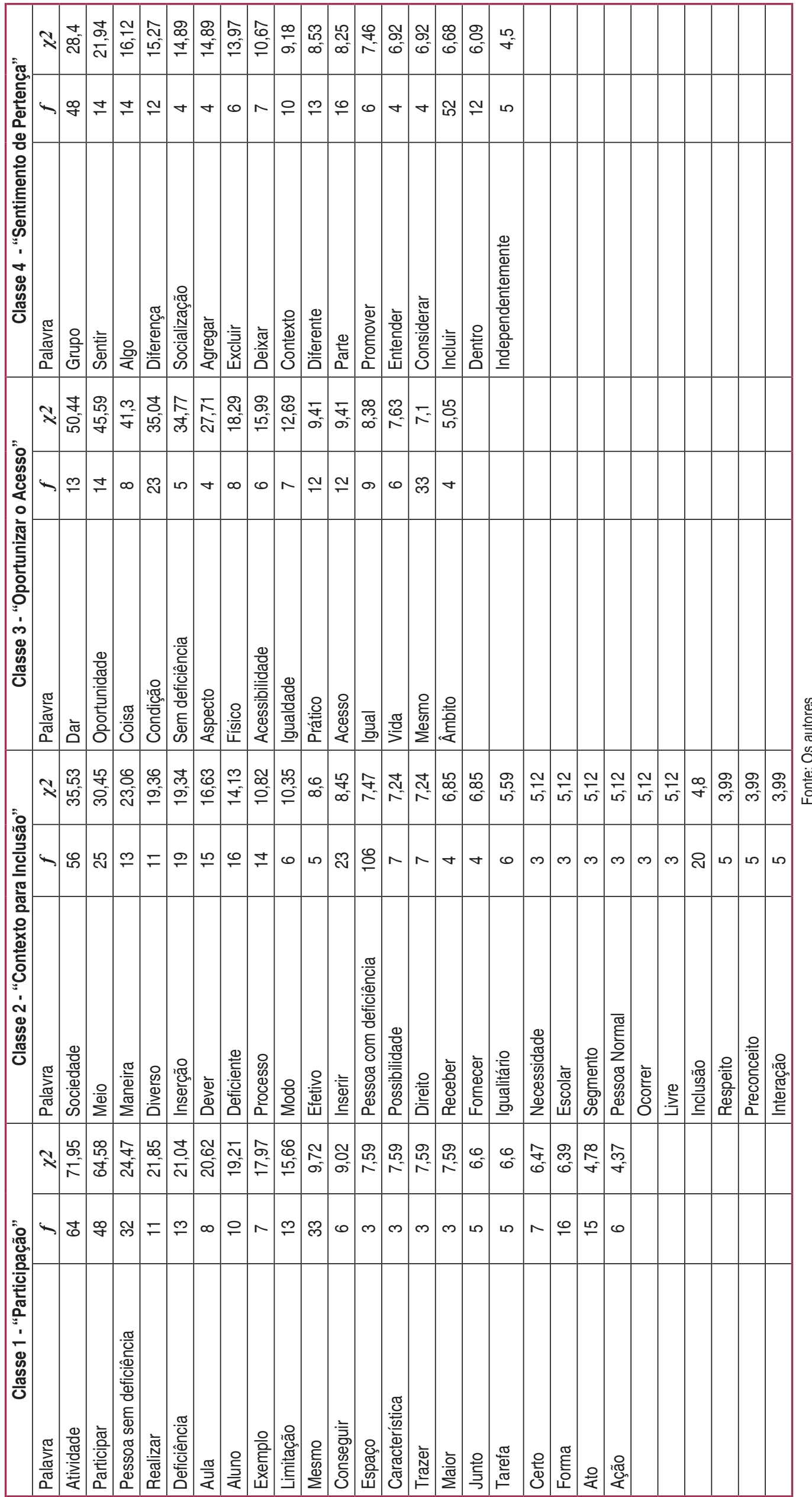
Por sua vez, a nuvem de palavras abaixo exposta retrata a frequência de palavras e 0 destaque observado na fala dos participantes.

Figura 1 - Nuvem de palavras da frequência de vocábulos proferidos pelos respondentes, segundo 0 software Iramuteq.

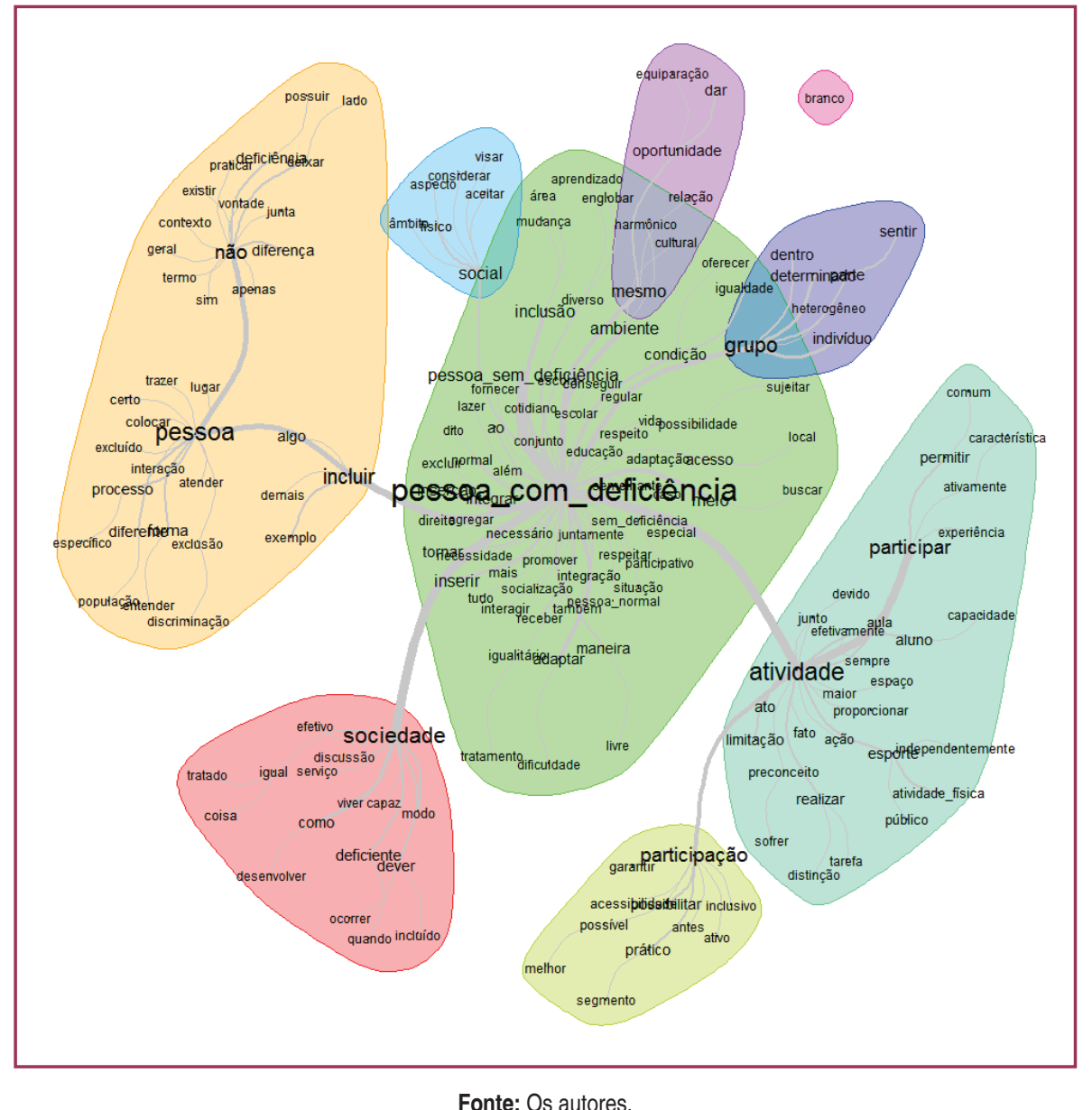

Os resultados referidos acima denotam um percurso de superação do contexto histórico com a implantação de novos conceitos na Educação Física. Os anteriores ideais militaristas, higienistas e eugenistas presentes no período de sua oficialização no território brasileiro em muitos momentos acentuaram as diferenças, excluindo os menos habilidosos, com desvantagens físicas, obesos ou tímidos (CASTELLANI FILHO, 2013). Conforme suas finalidades e funções foram repensadas, com novas abordagens e perspectivas para a área, houve uma reorganização dos currículos dos cursos de graduação em Educação Física, com maior equilíbrio entre as disciplinas de aspectos biológicos, esportivos e as de cunho humano pedagógico, associando-a aos novos ideais da área e da sociedade em construção.

Essa transformação exigiu uma imprescindível formação inicial e continuada nas quais fosse delineado um perfil docente propício à sociedade inclusiva, ou seja, capaz de trabalhar colaborativamente, de refletir sobre sua prática, de elaborar novas ações, avaliar sua efetividade e transformá-la de acordo com a exigência do seu aluno e da sociedade (FERREIRA, 2006).

A Educação Física necessitou capacitar seus docentes para reorganizar suas aulas de modo a permitir que todos desempenhassem uma participação ativa, interagindo efetivamente com os conhecimentos e conteúdos trabalhados; adaptando, para isso, não apenas uma 
atividade para uma condição específica de deficiência, mas planejando as aulas de forma permissível à participação de todos, com respeito às individualidades.

Em meio a essa imprescindibilidade, o conceito de inclusão apresentado pelos discentes concluintes de cursos de graduação em Educação Física de universidades públicas do estado de São Paulo que compuseram este estudo apresentou-se estruturado por quatro temáticas condizentes a essa vigente realidade: a "Participação", o "Contexto social para a inclusão", o "Oportunizar o acesso" e o "Sentimento de pertença".

Na primeira temática, os respondentes enfatizaram a participação das pessoas com deficiência por meio da inserção e atuação de todos na sociedade, com essas pessoas realizando as atividades o mais próximo possível da forma convencional, mas com as adaptações que se mostrassem necessárias.

Esses entendimentos dispõem de correlação com estudos afirmativos da participação de pessoas com dificuldades nas aulas de Educação Física requerer o oferecimento de meios que possibilitem sua atuação com qualidade, com procedimentos de adaptação das estruturas, funções ou do que se mostrar necessário.

Dentre esses estudos, a pesquisa de Munster (2013) atestou que o conceito inclusivo na Educação Física é relativo a permitir que todos participem da mesma atividade, ajustando-a com recursos, estratégias e conteúdos conforme despontarem dificuldades de participação do aluno na aula planejada. Para isso, Sherril (2004) dissertou que a adaptação deve ser contínua, recíproca e dinâmica, abarcando as variáveis relativas ao ambiente temporal e físico, equipamentos, materiais, ambiente psicossocial, aprendizagem, instrução, informação e relativas às tarefas.

Nesta conjuntura, a temática 1 mostrou-se intrinsicamente atrelada à segunda Classe de argumentos proferidos pelos respondentes, na qual foi direcionada a consideração ao contexto social propício à inclusão, atribuindo a responsabilidade do processo inclusivo para a sociedade, a qual deveria oferecer igualdade de oportunidades para todos.

As exposições da Classe 2 apresentaram-se em consonância com as discussões articuladas pelos organismos internacionais durante a apresentação da inclusão social aos demais países, bem como com as promulgações implantadas no Brasil. Elucidando essa afirmativa, na publicação das Normas Uniformes sobre a Igualdade de Oportunidades para Pessoas com Incapacidades, organizada pela Assembleia Geral das Nações Unidas, em 1993, foi recomendada a realização de programas de estudo sobre as deficiências e suas necessidades para garantir a participação dessas pessoas em todas as atividades da sociedade, ressaltando a necessidade dos Estados garantirem a igualdade de oportunidades às pessoas com deficiência (SILVA; SEABRA JUNIOR; ARAÚJO, 2008). Por sua vez, a Lei Brasileira $n^{0}$ 13.146, de 2015, redigiu o Estatuto da Pessoa com Deficiência garantindo a efetivação de um contexto social inclusivo e atribuindo a toda a sociedade a responsabilidade da consolidação de tais direitos (BRASIL, 2015).

Essa conformidade de entendimentos discentes com as ações legais também se estabeleceu na terceira temática, na qual o conceito inclusivo foi refletido de forma fundamentada na oportunização do acesso às pessoas com deficiência, considerando as questões concernentes à acessibilidade, ou seja, às estruturas necessárias para permitir a atuação de todos. 
A acessibilidade citada foi definida pela Lei $n^{0}$ 10.098, de 2000, como a "[...] possibilidade e condição de alcance para utilização, com segurança e autonomia, dos espaços, mobiliários e equipamentos urbanos, das edificações, dos transportes e dos sistemas e meios de comunicação", sendo assegurada, por esta mesma promulgação, sua promoção em todos os espaços e equipamentos públicos nacionais (BRASIL, 2000, p. 1).

Por fim, na Classe 4, os respondentes ponderaram sobre o sentimento de pertença, ou seja, a necessidade do acolhimento social durante a aproximação e socialização das pessoas em desvantagens. Neste ponto, os relatos expandiram a discussão inclusiva para 0 estabelecimento de relações afetivas, de ser aceito e valorizado.

Com as quatro temáticas aqui expostas, verifica-se que o conceito inclusivo apresentado pelos participantes deste estudo encontra similitude com as definições propostas internacionalmente. A Unesco (2008) oficializou a inclusão como um conceito complexo sustentado por quatro entendimentos: apresenta-se como um processo, ou seja, um percurso que demanda de ações permanentes; exige a identificação e a remoção de barreiras; deve estabelecer a presença e a participação social de todos com sucesso; e destina-se a todos, com atenção especial aos com risco de exclusão e marginalização.

A inclusão, portanto, vai além de uma alocação ou de fornecimento de uma estrutura física. Também envolve a adaptação de todo um contexto em seus aspectos arquitetônicos, conceituais e atitudinais, permitindo uma inserção física, mas também oferecendo medidas para que essa pessoa atue e interaja, que seja aceita e respeitada.

Os relatos apresentados pelos discentes participantes deste estudo mostraram uma compreensão do conceito de inclusão ser complexo e multivariado em suas exigências, o que pode ser verificado quando retomado que as classes temáticas englobaram citações concernentes às exigências legais associadas às necessidades sociais, permeadas por aspectos de diferentes dimensões humanas, como a afetiva e a psicológica.

Todavia, conforme visualizado na nuvem de palavras, o conceito inclusivo dos discentes limitou-se a focalizar a pessoa com a condição específica de deficiência a ser inserida como partícipe efetiva das atividades da sociedade conjuntamente às demais pessoas, e não a todos e, em especial, a grupos minoritários, conforme definição da Unesco supracitada (2008).

Por outro lado, apesar da maioria das respostas fornecidas associar a inclusão a uma população específica, alguns respondentes já direcionaram o ideal inclusivo a englobar a todos, independentemente das diferenças. Esses dados destacaram a ocorrência de um processo de transformação de entendimentos sobre a proposta inclusivista enquanto população-alvo e, consequentemente, sobre a sociedade enquanto um coletivo heterogêneo, com as diferenças a ela inatas.

Os apontamentos confirmaram o prelúdio de uma solidificação conceitual dos ideais inclusivos em substituição aos integracionistas, com predominância do entendimento da necessidade de adaptação social para o oferecimento de uma igualdade de oportunidades para a atuação ativa e com qualidade de todos, para além de uma mera alocação física nos espaços sociais.

Sabendo que, na sociedade, "[...] um paradigma não se esgota com a introdução de uma nova proposta, e que, na prática, todos esses modelos coexistem" (GLAT; FERNANDES, 
2005, p. 1), esse caminhar do entendimento de integração para o de inclusão, mas já com ideais muito mais próximos aos inclusivos, sugeriu uma tendência de superação dos anteriores paradigmas na formação docente.

Tais avanços de conhecimento teórico sobre o tema pode ser correlacionado à implantação da Resolução no 03 de 1987, por meio da qual o Conselho Federal de Educação instituiu a presença da disciplina de Educação Física Adaptada nos cursos superiores de Educação Física. Com isso, foram propiciadas discussões construtivas sobre a temática, contribuindo com a formação docente, ainda que em seus aspectos teóricos.

A ocorrência dessa reconstrução teórica pode ser confirmada quando comparadas as informações coletadas em estudos acadêmicos sobre a formação inicial e a atuação inclusiva na Educação Física ao longo dos anos. As primeiras pesquisas indicavam que a disciplina inserida na grade curricular sobre o tema tinha foco nos aspectos biológicos da deficiência com carência de aproximação entre teoria e prática, além de confusões terminológicas sobre a Inclusão, conforme apresentado por Schneider (1998). Já os estudos posteriores identificaram que, em diversas localidades do Brasil, como em Goiás (GONÇALVES, 2002), Mato Grosso do Sul (SILVA, 2005), Paraná (GOMES, 2007) e São Paulo (SALERNO, 2014), os cursos de graduação em Educação Física passaram a incorporar as diferentes dimensões humanas como alicerces para a discussão inclusiva, como sociais, culturais, educacionais e psicológicas, alcançando compreensões mais significativas pelos discentes acerca da questão, bem como uma inicial ainda que discreta aproximação da teoria com a prática por meio da implantação de ações, como visitas às instituições especializadas e às escolas regulares inclusivas, aulas práticas de simulações ou com a participação de alunos com necessidades educativas especiais.

Por conseguinte, podemos apurar que os dados aqui apresentados dispõem de correspondência com o conhecimento acadêmico obtido até então sobre a questão inclusiva na Educação Física. De fato, tem ocorrido uma reestruturação da formação inicial com qualificação dos futuros docentes de forma mais expressiva a essa realidade social em vigor.

Ponderando que as universidades públicas têm atuado enfaticamente na união entre ensino, extensão e pesquisa, este fator tem se desvelado benéfico para o alcance de reconstruções conceituais em direção às exigências sociais continuamente em transformação, como acerca da temática inclusiva.

Em contrapartida a esses resultados aqui obtidos, alguns estudos permaneceram apontando fragilidades na formação inicial da área concernentes à atuação inclusiva, atestando a manutenção de uma insegurança dos graduandos para uma futura intervenção com alunos com deficiência, bem como a permanência de dificuldades dos professores de Educação Física em atuação na realização de adaptações na organização didática, curricular, material, estrutural e de avaliação mesmo após vivenciaram uma formação com discussões sobre 0 tema da inclusão (CARVALHO, 2014; FILUS, 2011; SALERNO, 2014; SANCHES JUNIOR et al., 2015; SEABRA JUNIOR, 2012;).

Além disso, as dificuldades assinaladas também se referiram à falta de formação continuada para capacitar o docente com formação anterior à reconstrução do currículo da Educação Física para os desafios inerentes à prática (FIORINI; MANZINI, 2016).

Assim, este estudo detectou que as universidades públicas estaduais de São Paulo estão sendo eficazes na construção e oferecimento de conhecimentos aos seus discentes, 
sendo as críticas proferidas uma possível consequência da lentidão da sua chegada às diversas instituições de ensino superior, assim como da escassez de produção de conhecimentos por grande parte das instituições privadas, que atuam apenas com as esferas de ensino e, por vezes, extensão.

Certifica-se a relevância de uma formação inicial qualificada e articulada na tríade de ensino, pesquisa e extensão para a construção conceitual e condução procedimental da inclusão na Educação Física.

\section{CONSIDERAÇÕES FINAIS}

No presente estudo identificamos quatro classes de descritores nos relatos discentes, sendo elas "Participação", "Contexto social para a inclusão", "Oportunizar o acesso" e "Sentimento de Pertença". Segundo exposto na nuvem de palavras, sobressaiu-se um entendimento sobre a inclusão referir-se a uma pessoa com deficiência participando ativamente das atividades da sociedade conjuntamente às demais pessoas.

Sabendo que os programas de formação docente têm por função inovar e regular a prática docente segundo as necessidades de uma sociedade em transformação (PERRENOUD et al., 2007), constatamos que os discentes deste estudo, concluintes de cursos de graduação em Educação Física de universidades públicas do estado de São Paulo, têm alcançado um entendimento de inclusão em consonância com as propostas internacionais (UNESCO, 2008) e condizente com a complexidade do conceito, considerando aspectos legais, sociais, psicológicos e afetivos imbuídos nessa proposta.

Nessa conjuntura, caminhamos almejando a consolidação de uma Educação Física ao alcance de todos, na qual esteja assegurada a participação efetiva de todas as pessoas, independentemente de gênero, presença de uma deficiência ou outra condição de diferença (FINOCCHIO, 1991).

Para isso, são necessárias contínuas pesquisas para acompanhar a prática que esses discentes concluintes irão desenvolver, verificando a correlação entre a teoria aqui investigada com a ação pedagógica a ser desempenhada, assim como para investigar a qualificação dos inúmeros cursos de graduação existentes no país para além de universidades públicas paulistas.

\section{REFERÊNCIAS}

BRASIL. Lei n ${ }^{\circ}$ 10.098, de 19 de dezembro de 2000. Estabelece normas gerais e critérios básicos para a promoção da acessibilidade das pessoas portadoras de deficiência ou com mobilidade reduzida, e dá outras providências. Diário Oficial da República Federativa do Brasil, Brasília, DF, 19 dez. 2000. Disponível em: < www.planalto.gov.br/ccivil 03/leis/L10098.htm>. Acesso em: 18 jan. 2017.

BRASIL. Lei n 13.146, de 06 de julho de 2015. Institui a Lei Brasileira de Inclusão da Pessoa com Deficiência (Estatuto da Pessoa com Deficiência). Diário Oficial da República Federativa do Brasil, Brasília, DF, 6 jul. 2015. Disponível em: < https://www.planalto.gov.br/ccivil 03/ ato2015-2018/2015/ lei/l13146.htm. >. Acesso em: 2 de fev. de 2017. 
CAMARGO, Brigido; JUSTO, Ana Maria. IRAMUTEQ: um software gratuito para análise de dados textuais. Temas em Psicologia, Ribeirão Preto, v. 21, n. 2, p. 513-518, dez. 2013. Disponível em: $<$ http://pepsic.bvsalud.org/scielo.php?script=sci arttext\&pid=S1413-389X2013000200016\&lng=pt\&nrm =iso>. Acesso em: 4 out. 2017.

CARVALHO, Camila Lopes de. Conteúdos da educação física e a pedagogia de Freinet. 2014. 197f. Dissertação (Mestrado) - Faculdade de Educação Física, Universidade Estadual de Campinas, Campinas, 2014.

CASTELLANI FILHO, Lino. As concepções de Educação Física no Brasil. Horizontes, v.1, n.2, p. 11-31, jul./dez. 2013. Disponível em: <http://ojs.ufgd.edu.br/index.php/horizontes/article/view/3162>. Acesso em: 25 abr. 2017.

FERREIRA, Julio Romero. Educação Especial, inclusão e política educacional: notas brasileiras. In: RODRIGUES, Davi (Org.). Inclusão e educação: doze olhares sobre a educação inclusiva. São Paulo: Summus, 2006. p. 85-113.

FILUS, Josiane. Amarrações e arrumações na inclusão escolar do município de Hortolândia - SP. 2011. 199f. Tese (Doutorado) - Faculdade de Educação Física, Universidade Estadual de Campinas, Campinas, 2011.

FINOCCHIO, José Luiz. Trabalho, tempo livre e cultura física. 1991. 169f. Dissertação (Mestrado) - Centro de Ciências Humanas e Sociais, Universidade Federal de Mato Grasso do Sul, Mato Grasso do Sul, 1991.

FIORINI, Maria Luiza Salzani; MANZINI, Eduardo José. Concepção do professor de educação física sobre a inclusão escolar do aluno com deficiência. Debates em Educação, v. 8, n. 15, p.81-107, jan./ jun. 2016.

GLAT, Rosana; FERNANDES, Edicléa Mascarenhas. Da educação segregada à educação inclusiva: uma breve reflexão sobre os paradigmas educacionais no contexto da educação especial brasileira. Revista Inclusão, v.1, n.1, p.35-39, out. 2005.

GOMES, Nilton Munhoz. Análise da disciplina de educação física especial nas instituições de ensino superior públicas do estado do Paraná. 2007. 198f. Tese (Doutorado) - Faculdade de Educação Física, Universidade Estadual de Campinas, Campinas, 2007.

GONÇALVES, Vivianne Oliveira. Estudo da disciplina educação física adaptada nas instituições de ensino superior. 2002. 160f. Dissertação (Mestrado) - Faculdade de Educação Física, Universidade Estadual de Campinas, Campinas, 2002.

GORGATTI, Marcia Greguol; COSTA, Roberto Fernandes da. Atividade física adaptada. Barueri: Manole, 2005.

MUNSTER, Mey de Abreu Van. Inclusão de Estudantes com Deficiências em Programas de Educação Física: Adaptações Curriculares e Metodológicas. Revista da Associação Brasileira de Atividade Motora Adaptada, v. 14, n.2, p.27-34, jul./dez. 2013. Disponível em: <http://www2.marilia.unesp.br/ revistas/index.php/sobama/article/view/3612>. Acesso em: 14 fev. 2017.

PERRENOUD, Philippe et al. As competências para ensinar no século XXI: a formação dos professores e o desafio da avaliação. Porto Alegre: Artmed, 2007.

RATINAUD, Pierre. Iramuteq: Interface de R pour les Analyses Multidimensionnelles de Textes et de Questionnaires. Computer software, 2009. Disponível em: <http://www.iramuteq.org >. Acesso em: 4 out. 2017. 
SALERNO, Marina Brasiliano. A formação em educação física e o trabalho com a pessoa com deficiência. 2014. 184f. Tese (Doutorado) - Faculdade de Educação Física, Universidade Estadual de Campinas, Campinas, 2014.

SANCHES JUNIOR, Moisés et al. Concepções e práticas da inclusão na educação física escolar: estudo em uma cidade do Brasil. Educación Física y Deporte, Antioquia, v. 34, n. 1, p.155-179, ene/ jun. 2015. Disponível em: <http://doi.org/10.17533/udea.efyd.v34n1a07>. Acesso em: 12 ago. 2017.

SCHNEIDER, Cleuza. Proposta curricular voltada à pessoa com deficiência, para os cursos de graduação em educação física. 1998. 152f. Dissertação (Mestrado) - Escola de Educação Física, Universidade Federal do Rio Grande do Sul, Porto Alegre, 1998.

SEABRA JUNIOR, Luís. Educação física e inclusão educacional: entender para atender. 2012. 111f. Tese (Doutorado) - Faculdade de Educação Física, Universidade Estadual de Campinas, Campinas, 2012.

SHERRIL, Claudine. Adapted physical activity, recreation, and sport: cross disciplinary and lifespan. 6.ed. New York: Mac Graw-Hill, 2004.

SILVA, Rita de Fátima. A ação do professor de ensino superior na educação física adaptada: construção mediada pelos aspectos dos contextos históricos, políticos e sociais. 2005. 184f. Dissertação (Mestrado) - Faculdade de Educação Física, Universidade Estadual de Campinas, Campinas, 2005.

SILVA, Rita de Fátima; ARAÚJO, Paulo Ferreira de. Os caminhos da pesquisa em atividade motora adaptada. São Paulo: Phorte, 2012.

SILVA, Rita de Fátima; SEABRA JUNIOR, Luís; ARAÚJO, Paulo Ferreira de. Educação física adaptada no Brasil: da história à inclusão educacional. São Paulo: Phorte, 2008.

SMITH, Deborah. Introdução à educação especial: ensinar em tempos de inclusão. 5. ed. Porto Alegre: Artmed, 2008.

TABACHNICK, Barbara; FIDELL, Linda. Using Multivariate Statistics. Northridge: California State University, 2013.

UNESCO. Conclusions and recommendations of the 48th International Conference on Education. 2008. Disponível em: <http://www.ibe.unesco.org/en/ice/48th-ice-2008.html>. Acesso em: 14 fev. 2017.

UNESCO. Carta Internacional da Educação Física. Revista de Educação Física e Desportos, n. 8, 1981. Disponível em: < http://cev.org.br/biblioteca/carta-internacional-educacao-fisica-desportos/>. Acesso em: 15 out. 2017.

WINNICK, Joseph. Educação física e esportes adaptados. 3. ed. Barueri: Manole, 2004. 